\title{
Thin Film Electrodeposition of Ir(III) Cyclometallated Complexes
}

\author{
Andreea Ionescu, Iolinda Aiello, Alessandra Crispini, and Nicolas Godbert \\ MAT_INLAB (Laboratorio di Materiali Molecolari Inorganici), Centro di Eccellenza CEMIF.CAL, \\ LASCAMM CR-INSTM, Unità INSTM della Calabria, Dipartimento di Chimica e Tecnologie Chimiche, \\ Università della Calabria, 87036 Arcavacata di Rende (CS), Italy \\ Correspondence should be addressed to Andreea Ionescu; andreea.ionescu@unical.it
}

Received 4 November 2015; Accepted 6 December 2015

Academic Editor: Frederic Dumur

Copyright (C) 2016 Andreea Ionescu et al. This is an open access article distributed under the Creative Commons Attribution License, which permits unrestricted use, distribution, and reproduction in any medium, provided the original work is properly cited.

Novel electropolymerizable $\operatorname{Ir}(\mathrm{III})$ cyclometallated complexes have been synthesized and characterized. In these complexes the cyclometallated ligands are either 2-phenylpyridine $\mathbf{H}(\mathbf{P h P y})$ or benzothiazole-triphenylamine $\mathbf{H}(\mathbf{B z T h}$-tpa), while the Ir(III) coordination sphere is completed by a Schiff base substituted with a triphenylamine fragment. A complete electrochemical study has been conducted on all complexes, in order to verify the feasibility of electropolymerization and to elucidate the role of the specific position of the triphenylamine moiety in the molecular structure. Homogeneous thin films of Ir(III) metallopolymers have been successfully obtained through electropolymerization process.

\section{Introduction}

Metallopolymers represent a fast rising class of functional materials due to their combined specific properties induced by metal centers and the processability and low cost of synthetic polymers [1]. Since the first reported poly(vinylferrocene) [2], metallopolymers (especially those containing $\mathrm{d}$ - and f-block metals) have been used in optoelectronic (super/semiconductors, electrochromic, and luminescent devices) and catalysis processes. Many polymerization techniques have been employed in the synthesis of metallopolymers, including "living" polymerization routes and self-assembling methods [3]. Nevertheless, the controlled deposition of high quality polymeric films on different substrates, a key step towards functional applications, still represents a challenge.

In the case of deposition of metallopolymers, electropolymerization presents several advantages over the different film generating methods based on transition metal complexes, like layer-by-layer assembly [4], spin-casting [5], drop-casting [6], or electrostatic binding in the case of polyelectrolyte films [7]. In the electropolymerization process, the polymer formation and its deposition occur simultaneously, avoiding limitation such as scarce solubility of polymeric networks and leading to controllable film composition, thickness, and surface coverage [8].

The first reports on the electrodeposition of organometallic monomers are referred to the reductive electropolymerization of vinyl-substituted polypyridine complexes [9]. Up to date, different electropolymerizable groups such as thiophene $[10,11]$, pyrrole [12], aromatic amines [13-15], and diphenylamino $[16,17]$ have been introduced in organometallic compounds. The obtained neutral and ionic complexes of different metal centers ( $\mathrm{Ru}, \mathrm{Os}, \mathrm{Fe}$, and Ir) [8] have afforded the in situ preparation and the deposition of metallopolymeric films on different conducting substrates.

In this context, a series of electropolymerizable cyclometallated square planar photoconductive $\mathrm{Pd}(\mathrm{II})$ and $\mathrm{Pt}(\mathrm{II}) \mathrm{com}$ plexes, containing as ancillary ligand a Schiff base substituted with a triphenylamine group, were recently reported by our group (Scheme 1). The use of this specifically functionalized Schiff base ligands has been the key factor in the induction of an electropolymerization process during repetitive potential scans, allowing the deposition of highly stable and homogeneous electroactive and photoconductive $\mathrm{Pd}(\mathrm{II})$ and $\mathrm{Pt}(\mathrm{II})$ metallopolymers [18]. 
<smiles>COc1ccc(OC)c(/C=N\c2ccc(N(c3ccccc3)c3ccccc3)cc2)c1</smiles>

$\mathrm{M}=\mathrm{Pd}(\mathrm{II})$ or $\mathrm{Pt}(\mathrm{II})$

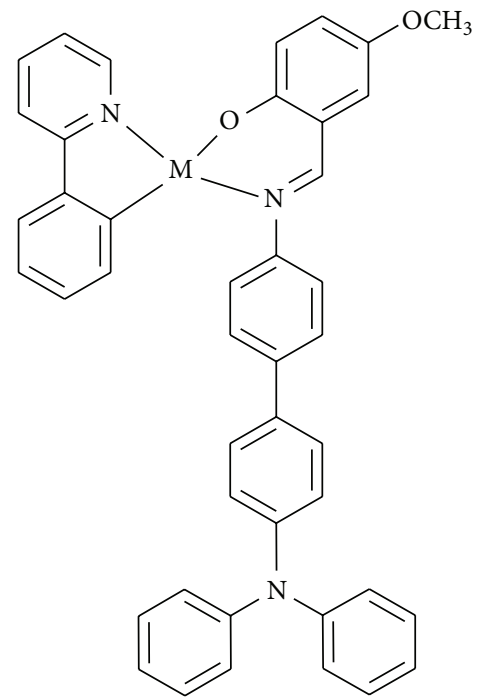

$\mathrm{M}=\mathrm{Pd}(\mathrm{II})$ or $\mathrm{Pt}(\mathrm{II})$

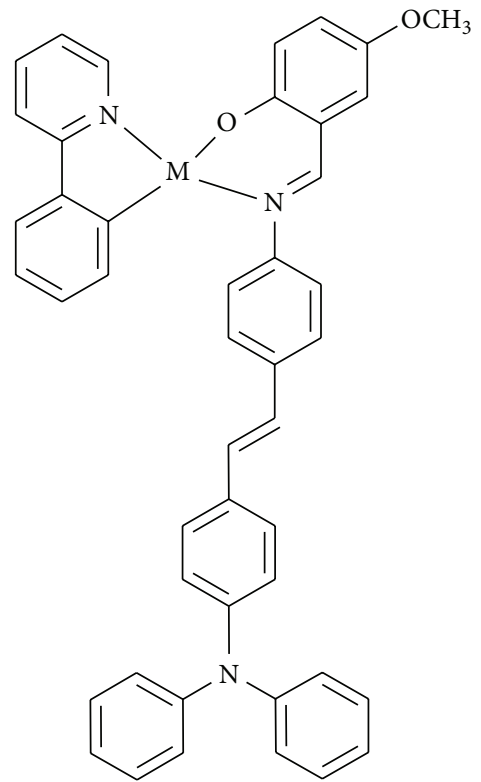

$\mathrm{M}=\mathrm{Pd}(\mathrm{II})$ or $\mathrm{Pt}(\mathrm{II})$

SCHeme 1: Electropolymerizable Pd(II)/Pt(II) complexes from [18].

The choice of the triphenylamine substituent as a potential electropolymerizable fragment has been motivated by its ability to form cross-linked conjugated polymeric networks, favouring isotropic charge transport and showing high electrochemical stability $[16,17,19]$.

In order to extend the developed electrodeposition method towards octahedral complexes, we have incorporated the triphenylamine electropolymerizable Schiff base $\mathbf{H}\left(\mathbf{O}^{\wedge} \mathbf{N}\right)_{\text {tpa }}$ (Figure 1) into Ir(III) cyclometallated complexes. Therefore, herein a series of new cyclometallated $\operatorname{Ir}(\mathrm{III})$ complexes containing the electropolymerizable Schiff base $\mathbf{H}\left(\mathbf{O}^{\wedge} \mathbf{N}\right)_{\text {tpa }}$ is reported, together with corresponding model complexes as direct comparison, where the $\mathbf{H}\left(\mathbf{O}^{\wedge} \mathbf{N}\right)_{\mathbf{C 6}}$ Schiff base ligand is lacking the electropolymerizable group (Figure 1).

A complete electrochemical study has been performed on the novel complexes I-IV, in order to establish their redox behaviour and to probe the electrodeposition feasibility as high quality thin films.

\section{Materials and Methods}

All commercially available chemicals were purchased from Aldrich Chemical Co. and were used without further purification. IR spectra ( $\mathrm{KBr}$ pellets) were recorded on a PerkinElmer Spectrum One FT-IR spectrometer. ${ }^{1} \mathrm{H}$-NMR spectra were recorded on a Bruker WH-300 spectrometer in deuterated solvents with TMS as an internal standard. Elemental analyses were performed with a Perkin-Elmer 2400 analyzer CHNS/O. Melting points were examined with a Leica DMLP polarising microscope equipped with a Leica DFC280 camera and a CalCTec (Italy) heating stage.

All potentials were measured using an Epsilon electrochemical analyser. Voltammetry experiments were performed in a $3 \mathrm{~mL}$ cell of dry and degassed $\left(\mathrm{N}_{2}\right)$ dichloromethane solution using tetrabutylammonium hexafluorophosphate $(0.1 \mathrm{M})$ as a supporting electrolyte, a Pt disk working as electrode, a Pt wire as counterelectrode, and an Ag wire as a pseudoreference electrode. Voltammograms were recorded at a $100 \mathrm{mV} \mathrm{s}^{-1}$ scan rate from $\mathrm{ca} \cdot 10^{-3} \mathrm{M}$ complex solutions. Redox potentials are given relative to a ferrocene/ferrocenium $\left(\mathrm{Fc} / \mathrm{Fc}^{+}\right)$redox couple used as an internal reference. Estimation of HOMO/LUMO energy values was performed taking into account $-4.8 \mathrm{eV}$ for the couple $\mathrm{Fc} / \mathrm{Fc}^{+}$[20].

\section{Results and Discussion}

3.1. Synthesis. The two first synthesized Ir(III) model complexes I and II contain the PhPy fragment as cyclometallated ligands and the Schiff bases $\mathbf{H}\left(\mathbf{O}^{\wedge} \mathbf{N}\right)_{\mathbf{C} 6}$ [21] and $\mathbf{H}\left(\mathbf{O}^{\wedge} \mathbf{N}\right)_{\text {tpa }}$ [18], respectively, as ancillary ligands. In order to complete the comparing series of Ir(III) complexes and study the influence of the position of the TPA fragment on the coordinated ligands with respect to the electropolymerization process, the two cyclometallated benzothiazoletriphenylamine $\operatorname{Ir}(\mathrm{III})$ complexes III and IV, containing the same Schiff bases $\mathbf{H}\left(\mathbf{O}^{\wedge} \mathbf{N}\right)_{\mathbf{C} 6}$ and $\mathbf{H}\left(\mathbf{O}^{\wedge} \mathbf{N}\right)_{\text {tpa }}$, were synthesized.

The synthesis of all the complexes I-IV (Scheme 2) was achieved starting from their corresponding dichlorobridged dimer. In particular, complexes I and II were obtained starting from the already described chlorobridged dimer 1 [22]. In the case of complexes III and IV, after synthesizing the cyclometallating ligand $\mathbf{H}$ (BzTh-tpa) [23], the corresponding dichlorobridged cyclometallated $\operatorname{Ir}(\mathrm{III})$ intermediate $\mathbf{2}$ was obtained by modification of the reported procedure [23].

Finally, through bridge splitting reaction between the respective bridged intermediate and the appropriate 


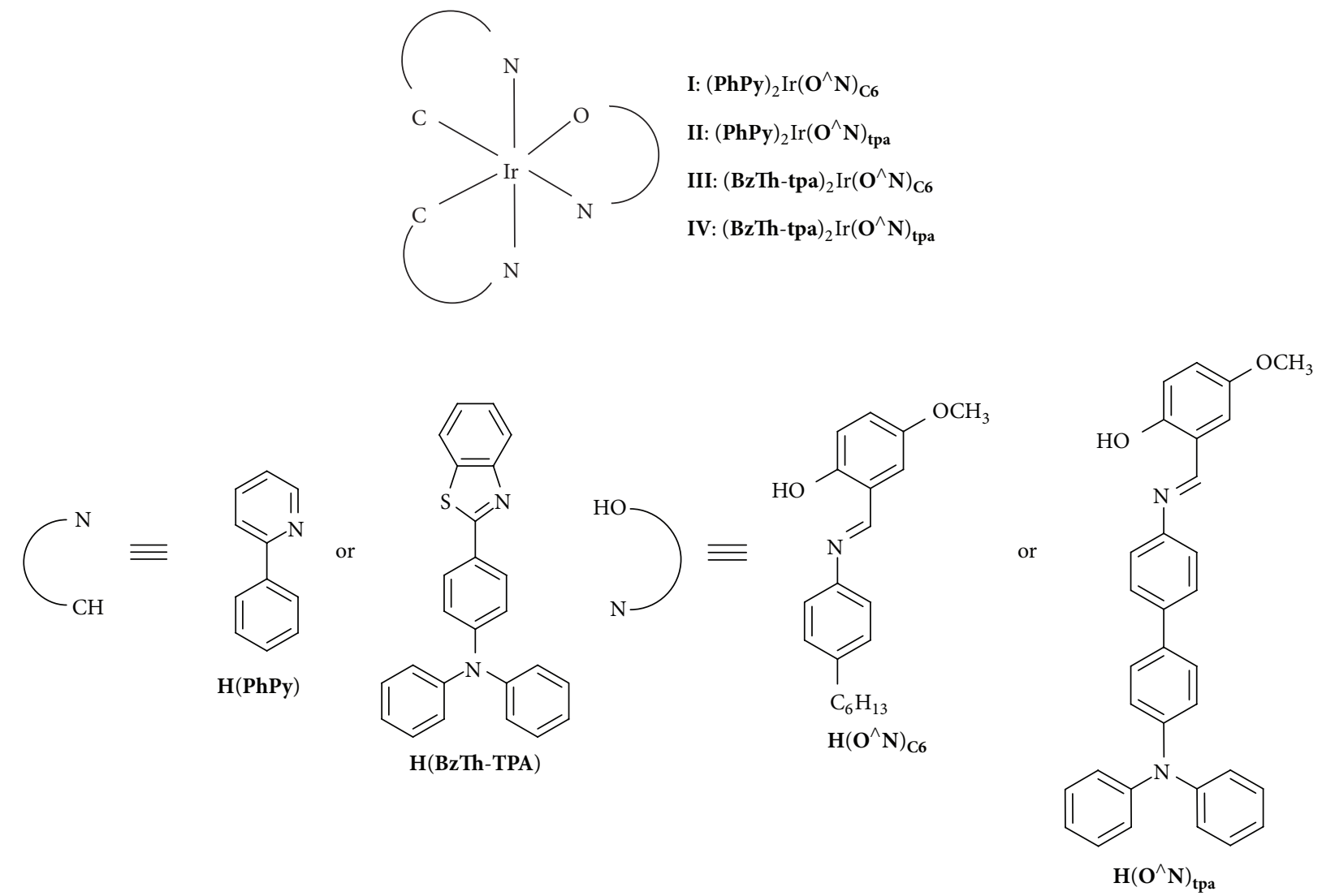

Figure 1: Molecular structures of the synthesized Ir(III) complexes I-IV and the O-, N-coordinated ligands.

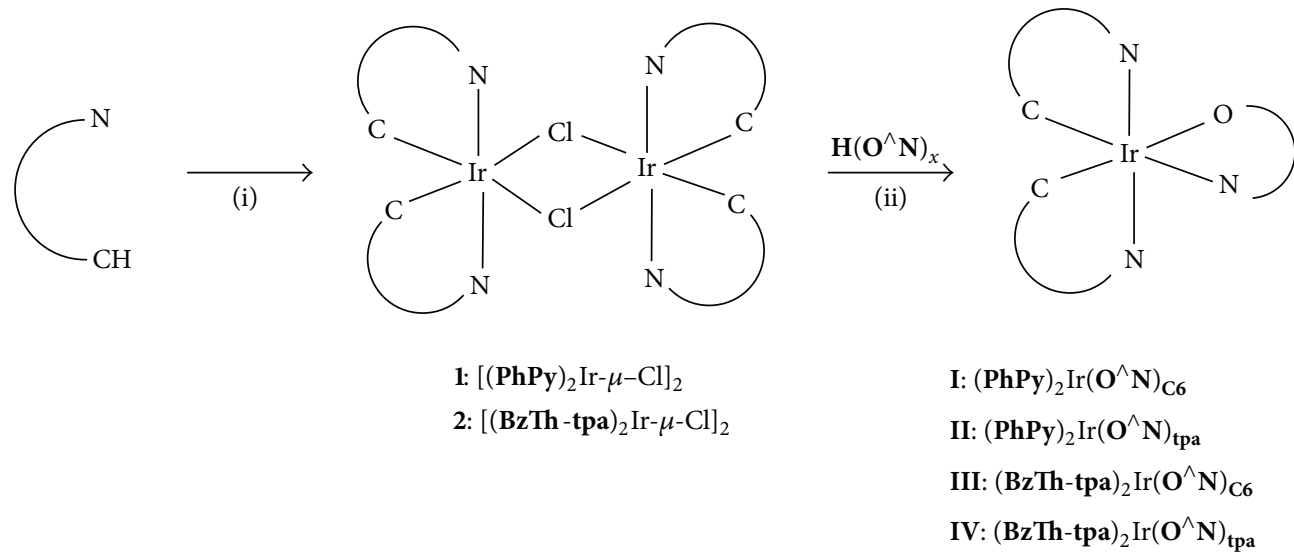

Scheme 2: Reagents and conditions: (i) for 1: 2-ethoxyethanol/water: 3/1, reflux, $48 \mathrm{~h}$; for 2: ethoxyethanol/water: 3/1, reflux, $4 \mathrm{~d}$., $\mathrm{N}_{2}$; (ii) dichloromethane/acetone, reflux, $48 \mathrm{~h}$.

substituted Schiff base, in the presence of an excess of trimethylamine for the complete deprotonation of the ancillary ligand, a single isomer of the final complexes I-IV was obtained in overall high yields.

3.2. Electrochemical Studies. Complexes I-IV redox behaviour was studied by cyclic voltammetry. The measured oxidation potentials and the estimated HOMO levels are reported in Table 1, together with the $\mathbf{H}(\mathbf{B z T h}$-tpa) ligand oxidation potential added for direct comparison. The corresponding obtained cyclic voltammograms are shown in Figure 2.

Considering the oxidation behaviour of the model complexes I-II (Figure 2(a)), the single reversible one-electron wave seen in the case of complex I can be attributed to the Schiff base $\mathbf{H}\left(\mathbf{O}^{\wedge} \mathbf{N}\right)_{\mathbf{C 6}}$ oxidation, while the two consecutive oxidation waves observed in the cyclic voltammogram of II are typical of the triphenylamine moiety of the $\mathbf{H}\left(\mathbf{O}^{\wedge} \mathbf{N}\right)_{\text {tpa }}$ Schiff base [18]. 


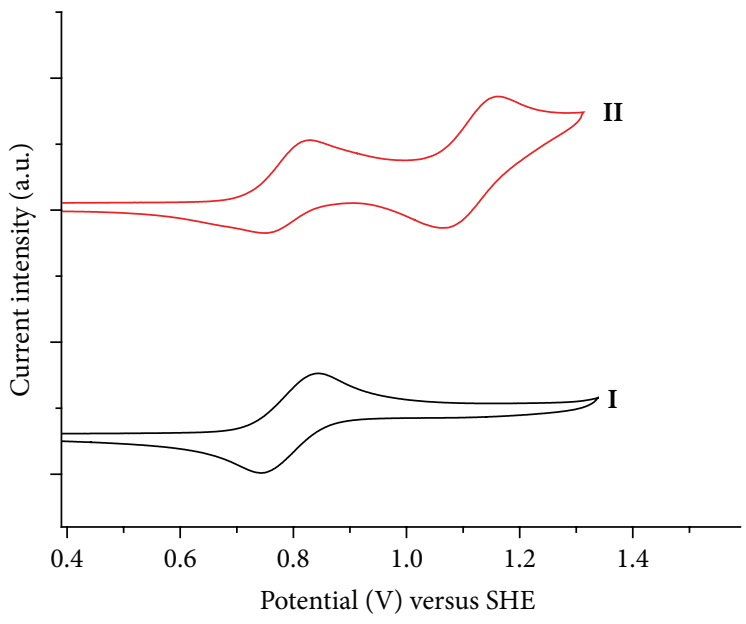

(a)

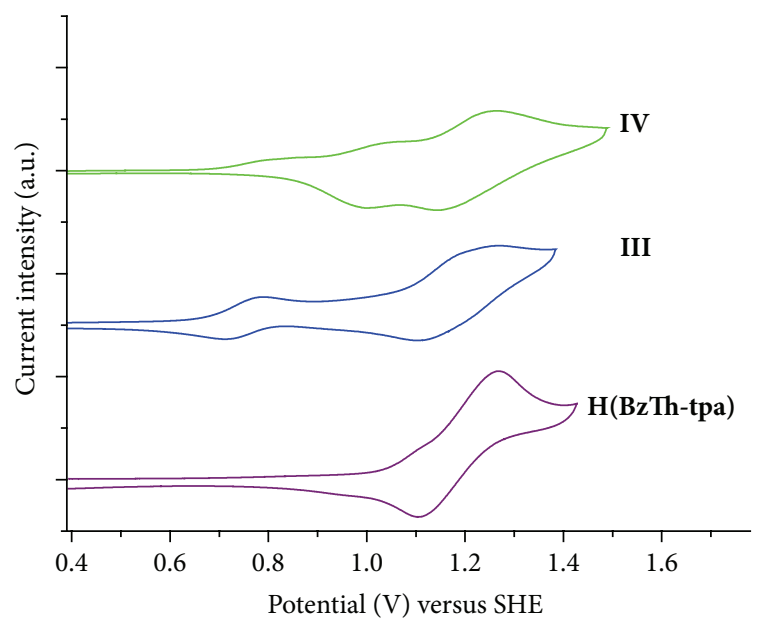

(b)

FIGURE 2: Cyclic voltammograms of (a) complexes I-II and (b) ligand $\mathbf{H}\left(\mathbf{B z T h}\right.$-tpa) and complexes III-IV. Scan rate $100 \mathrm{mV} \mathrm{s}{ }^{-1}$ in dry dichloromethane.

TABLE 1: Cyclic voltammetry data relative to complexes I-IV and H(BzTh-tpa). $E_{\text {ox }}{ }^{n}, n=1,2,3$, refer to the oxidation waves recorded on increasing potential. Estimated HOMO.

\begin{tabular}{lcccc}
\hline & $E_{\text {ox }}{ }^{1}(\mathrm{mV})$ & $E_{\text {ox }}{ }^{2}(\mathrm{mV})$ & $E_{\text {ox }}{ }^{3}(\mathrm{mV})$ & HOMO $(\mathrm{eV})$ \\
\hline I & $+165(\mathrm{R})$ & $/$ & $/$ & -5.0 \\
II & $+190(\mathrm{R})$ & $+510(\mathrm{R})$ & $/$ & -5.0 \\
H(BzTh-tpa) & $+545(\mathrm{R})$ & $/$ & $/$ & -5.3 \\
III & $+150(\mathrm{R})$ & $+530(\mathrm{R})$ & $/$ & -4.9 \\
IV & $+162(\mathrm{QR})$ & $+370(\mathrm{R})$ & $+545(\mathrm{R})$ & -5.0 \\
\hline
\end{tabular}

All potentials are given versus $\mathrm{Fc} / \mathrm{Fc}^{+}$. (R): reversible wave; $(\mathrm{QR})$ : quasireversible.

For the two reversible oxidation waves observed in the case of complex III, the first one is probably associated with the Schiff base $\left(\mathbf{O}^{\wedge} \mathbf{N}\right)_{\mathbf{C 6}}$, while the second reversible wave can reasonably be attributed to the oxidation of the cyclometallated ligand [24], H(BzTh-tpa) showing, in the solvent window explored $(-1.2-1.45 \mathrm{~V})$, a single reversible oxidation at ca. $+545 \mathrm{mV}$ versus $\mathrm{Fc} / \mathrm{Fc}^{+}$.

Regarding the oxidation properties of complex IV, a specific and unambiguous attribution of the oxidation processes on a molecular scale resulted to be unfeasible due to the overlap of the oxidation waves of the various fragments. However, according to the potential value of the first quasireversible wave, this oxidation process can be reasonably attributed to the first oxidation process of the $\mathbf{H}\left(\mathbf{O}^{\wedge} \mathbf{N}\right)_{\text {tpa }}$ Schiff base ligand. For all complexes I-IV, no reduction wave was recorded in the allowed solvent window $(-1.2-1.45 \mathrm{~V})$.

As expected for complex I, no electropolymerization process was observed upon repetitive potential scan cycles, but neither for complex II containing the $\left(\mathbf{O}^{\wedge} \mathbf{N}\right)_{\text {tpa }}$ triphenylamine substituted Schiff base nor for complex III, where the triphenylamine fragment is on the cyclometallated ligand, such electropolymerization processes were recorded (Figure 3). The slight increase in the current intensity visible on the respective cyclic voltammograms is only due to minor accumulation of oxidized specie at the surface electrode.

From these observations, we can conclude that for the triphenylamine moieties incorporated either in the Schiff base (complex II) or in the cyclometallated ligand (BzThtpa) (complex III) the electropolymerization is prevented, probably due to electronic factors induced by the nature of the other ligands surrounding the Ir(III) center. Indeed, as previously reported, the presence of electrowithdrawing substituents in paraposition with respect to triphenylamine fragments highly controls the electropolymerization process in which these units are involved [25].

On the contrary, upon repetitive oxidation scans, a distinctive regular increase in current is observed in the cyclic voltammogram of IV, which is typical of the electropolymerization of the substituted triphenylamine fragment (Figure 4(a)) [23]. In this case, the synergistic electronic contribution of all substituents on both the cyclometallated and the ancillary ligands produces an overall withdrawing effect able to allow the electropolymerization of the triphenylamine fragment of the $\left(\mathbf{O}^{\wedge} \mathbf{N}\right)_{\text {tpa }}$ Schiff base.

Once the polymer was formed, the modified Pt disk working electrode covered with complex IV electropolymerized film was immersed in a freshly distilled dichloromethane solution ( $0.1 \mathrm{M}$ electrolytic solution). The recorded cyclic voltammogram proved the electroactivity and stability of the deposited film (Figure 4(b)).

Electrogenerated thin films of IV were deposited on ITO etched glass substrates. A cyclic voltammogram recorded upon electropolymerization of IV onto an ITO glass substrate is shown in Figure 5 together with the photography of the obtained deposited thin film.

\section{Conclusions}

Novel biscyclometallated $\operatorname{Ir}($ III) complexes (I-IV), bearing (PhPy) or (BzTh-tpa) as cyclometallated ligand as well as 


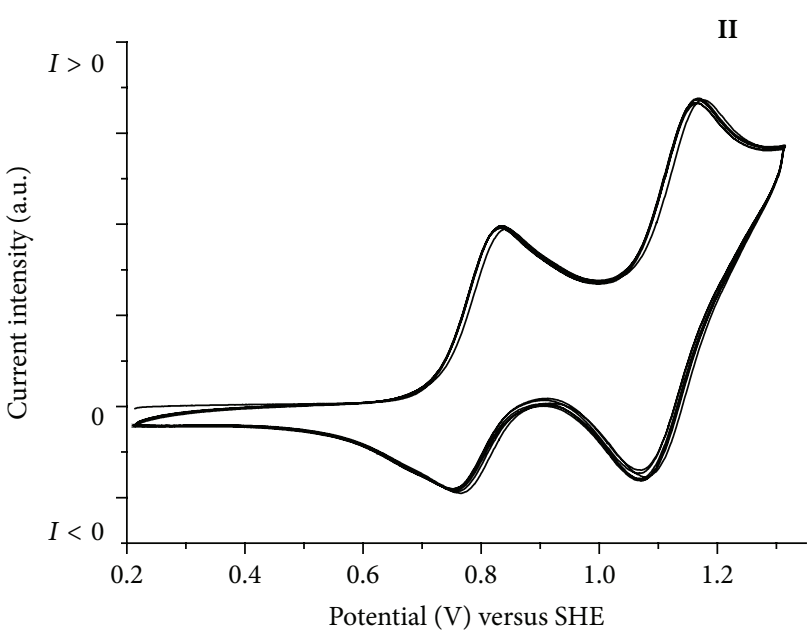

(a)

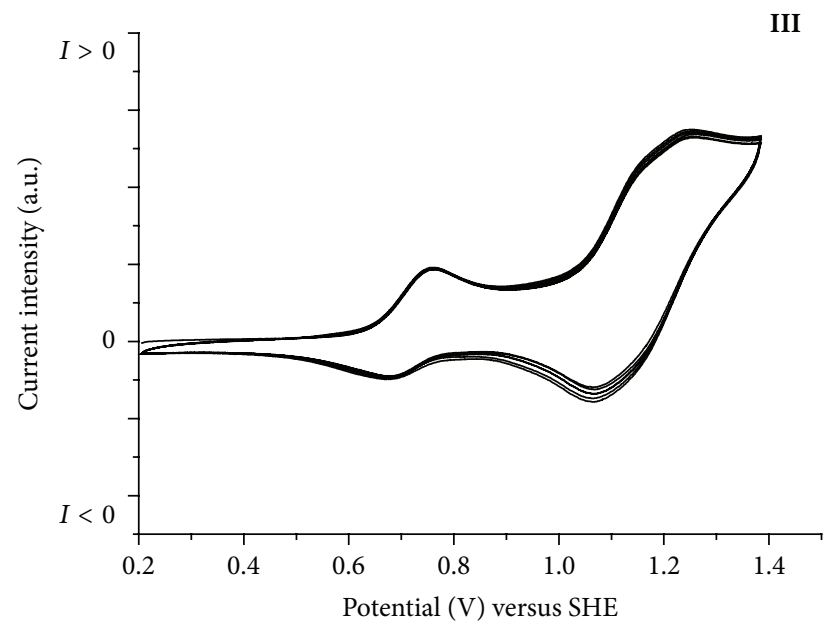

(b)

FIGURE 3: Cyclic voltammograms of (a) II and (b) III obtained from six consecutive oxidation scans.

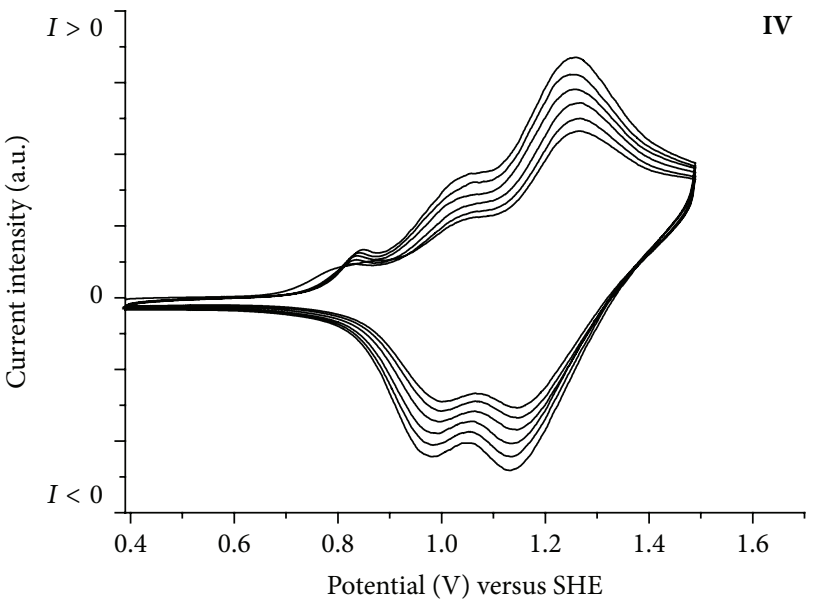

(a)

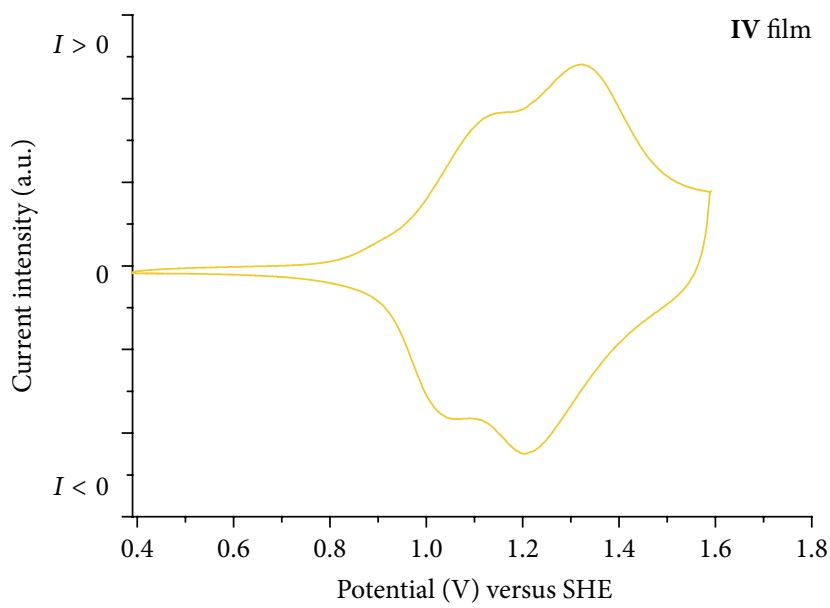

(b)

Figure 4: (a) Cyclic voltammograms of IV obtained from six consecutive oxidation scans and (b) cyclic voltammogram in fresh dichloromethane electrolytic solution of the resulting modified Pt electrode obtained after 20 cycles.

substituted Schiff bases as $\left(\mathbf{O}^{\wedge} \mathbf{N}\right)$ chelated ancillary ligand, have been synthesized. A complete electrochemical study has been performed on all complexes. It has been observed that electropolymerization of the triphenylamine fragment is highly dependent onto the nature of the ligands incorporated within the coordination sphere of the metal ion. Indeed, the introduction of the triphenylamine fragment on the Schiff base $\left(\mathbf{O}^{\wedge} \mathbf{N}\right)_{\text {tpa }}$ ligand in the presence of the cyclometallated (BzTh-tpa) ligands favoured the electropolymerization process. Upon repetitive potential scans, high quality polymeric thin films of complex IV have been electrodeposited on ITO covered glass electrodes. The presence of the triphenylamine fragment in the Schiff base represents thus a necessary condition in order to induce electropolymerization. However, the described results of the electrochemical study proved that this condition is not sufficient, as demonstrated by the lack of electropolymerization in the case of complex II bearing (PhPy) fragments as cyclometallated ligands. Furthermore, investigations of the photophysical and electrochromic properties of these metallopolymers are in progress, in order to test the potential application of $\operatorname{Ir}(\mathrm{III})$ thin films in electroluminescent and/or electrochromic devices.

\section{Experimental Details}

5.1. Synthesis of Complex I. Intermediate complex 1 [22] $(150 \mathrm{mg}, 0.14 \mathrm{mmol})$ was solubilized in $c a .50 \mathrm{~mL}$ of a $1: 1$ mixture of acetone and chloroform. 2 eqs. of $\mathbf{H}\left(\mathbf{O}^{\wedge} \mathbf{N}\right)_{\mathbf{C 6}}$ [21] $(87 \mathrm{mg}, 0.28 \mathrm{mmol})$ and 30 eqs. $(0.3 \mathrm{~mL}, 4.2 \mathrm{mmol})$ of trimethylamine were added to the solution. The reaction mixture was stirred at reflux for $72 \mathrm{~h}$. The solvent was evaporated and the organic phase extracted with dichloromethane/water and dried over sodium sulphate. The crude product was purified by precipitation from dichloromethane $/ n$-hexane. The solid was filtered off, washed with hexane, and dried under vacuum. 


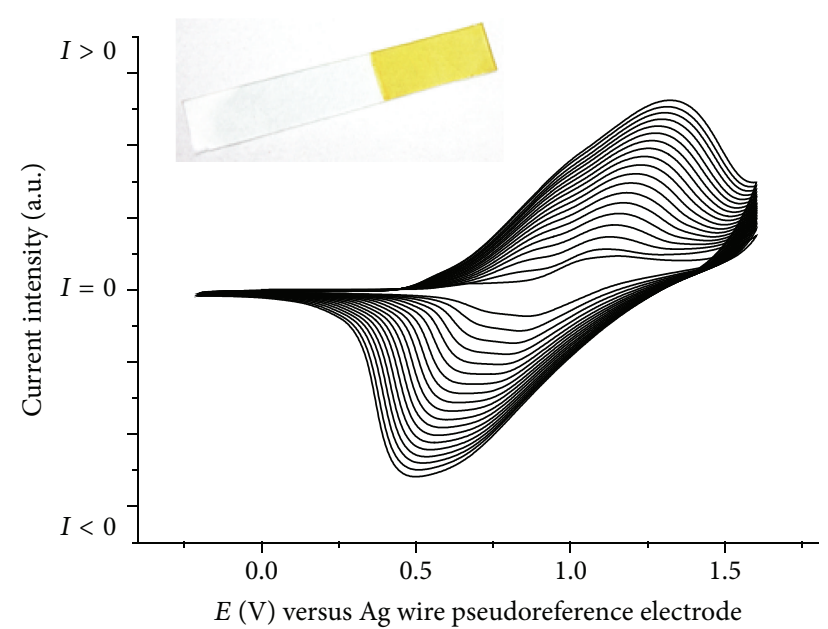

FIGURE 5: Electropolymerization of IV on ITO substrate (20 cycles).

Red solid; yield 66\% (149 mg); m.p. > 250 ${ }^{\circ}$; ${ }^{1} \mathrm{H}$ NMR $\left(300 \mathrm{MHz} \mathrm{CDCl}_{3}, 25^{\circ} \mathrm{C}, \mathrm{TMS}\right) \delta=8.92(\mathrm{~d}, J=5.49 \mathrm{~Hz}, 1 \mathrm{H})$, $8.86(\mathrm{~d}, J=5.79 \mathrm{~Hz}, 1 \mathrm{H}), 8.05(\mathrm{~s}, 1 \mathrm{H}), 7.88(\mathrm{~d}, J=8.37 \mathrm{~Hz}$, $1 \mathrm{H}), 7.67(\mathrm{~d}, J=13 \mathrm{~Hz}, 1 \mathrm{H}), 7.68(\mathrm{t}, J=14 \mathrm{~Hz}, 1 \mathrm{H}), 7.59(\mathrm{~d}$, $J=7.83 \mathrm{~Hz}, 1 \mathrm{H}), 7.51(\mathrm{~d}, J=8.1 \mathrm{~Hz}, 1 \mathrm{H}), 7.12(\mathrm{t}, J=5.76 \mathrm{~Hz}$, $1 \mathrm{H}), 7.06-7.00(\mathrm{~m}, 2 \mathrm{H}), 6.95(\mathrm{dd}, J=9.18 \mathrm{~Hz}, J=3.3 \mathrm{~Hz}$, $1 \mathrm{H}), 6.85(\mathrm{t}, J=7.95 \mathrm{~Hz}, 1 \mathrm{H}), 6.72(\mathrm{t}, J=7.26 \mathrm{~Hz}, 1 \mathrm{H}), 6.65$ $(\mathrm{d}, J=9.18 \mathrm{~Hz}, 1 \mathrm{H}), 6.57(\mathrm{~d}, J=3.3 \mathrm{~Hz}, 1 \mathrm{H}), 6.51-6.49(\mathrm{~m}$, $4 \mathrm{H}), 6.28(\mathrm{~d}, J=7.26 \mathrm{~Hz}, 1 \mathrm{H}), 6.17(\mathrm{~d}, J=7.69 \mathrm{~Hz}, 1 \mathrm{H}), 6.02$ $(\mathrm{d}, J=8.25 \mathrm{~Hz}), 3.71(\mathrm{~s}, 3 \mathrm{H}), 2.35(\mathrm{t}, J=7.56 \mathrm{~Hz}, 2 \mathrm{H}), 1.67-$ $1.22(\mathrm{~m}, 8 \mathrm{H}), 0.93\left(\mathrm{t}, \mathrm{J}=6.72 \mathrm{~Hz}, 3 \mathrm{H},-\mathrm{OCH}_{3}\right)$; FT-IR $(\mathrm{KBr}$, $\mathrm{cm}^{-1}$ ): 3041, 2996, 2925, 2853 (alkyl stretching), 1620 (CN Schiff base), 1604, 1584, 1476, 1465, 1425, 1314, 1212, 1147, 1030, 755, 729; elemental analysis calculated for $\mathrm{C}_{42} \mathrm{H}_{40} \mathrm{IrN}_{3} \mathrm{O}_{2}$ (811.00 g/mol): C 62.20\%, H 4.97\%, N 5.18\%, found C 62.50\%, H 5.14\%, N 5.20\%.

5.2. Synthesis of Complex II. 1 (100 mg, $0.09 \mathrm{mmol})$ was solubilized in $c a .50 \mathrm{~mL}$ of a 1:1 mixture of acetone and chloroform. 2 eqs. of $\mathbf{H}\left(\mathbf{O}^{\wedge} \mathbf{N}\right)_{\text {tpa }}$ [18] $(88 \mathrm{mg}, 0.18 \mathrm{mmol})$ and 30 eqs. $(0.2 \mathrm{~mL}, 2.8 \mathrm{mmol})$ of trimethylamine were added to the solution. The reaction mixture was stirred at reflux for $72 \mathrm{~h}$. The solvent was evaporated and the organic phase extracted with dichloromethane/water and dried over sodium sulphate. The crude product was purified by precipitation from dichloromethane/hexane. The solid was filtered off, washed with $n$-hexane, and dried under vacuum.

Red solid; yield 80\% (145 mg); m.p. > 250 ${ }^{\circ}$; ${ }^{1} \mathrm{H}$ NMR $\left(300 \mathrm{MHz}, \mathrm{CDCl}_{3}, 25^{\circ} \mathrm{C}\right.$, TMS $) \delta=8.93(\mathrm{~d}, J=5.34 \mathrm{~Hz}$, $1 \mathrm{H}), 8.89(\mathrm{~d}, J=5.49 \mathrm{~Hz}, 1 \mathrm{H}), 7.89(\mathrm{~d}, J=8.1 \mathrm{~Hz}, 1 \mathrm{H})$, $7.75-7.59(\mathrm{~m}, 3 \mathrm{H}), 7.50(\mathrm{~d}, J=8.1 \mathrm{~Hz}, 1 \mathrm{H}), 7.31-7.22(\mathrm{~m}$, $4 \mathrm{H}), 7.14-7.02(\mathrm{~m}, 13 \mathrm{H}), 6.99-6.95(\mathrm{~m}, 1 \mathrm{H}), 6.89-6.83(\mathrm{~m}$, $3 \mathrm{H}), 6.75-6.65(\mathrm{~m}, 2 \mathrm{H}), 6.59(\mathrm{~d}, J=3.18 \mathrm{~Hz}, 1 \mathrm{H}), 6.56-$ $6.54(\mathrm{~m}, 2 \mathrm{H}), 6.29(\mathrm{~d}, J=7.68 \mathrm{~Hz}, 1 \mathrm{H}), 6.22-6.19(\mathrm{~m}$, $1 \mathrm{H}), 6.16(\mathrm{~d}, J=8.25 \mathrm{~Hz}, 2 \mathrm{H}), 3.72\left(\mathrm{~s}, 3 \mathrm{H},-\mathrm{OCH}_{3}\right)$; FTIR $\left(\mathrm{KBr}, \mathrm{cm}^{-1}\right)$ : 3030, 2920, 2833 (alkyl stretching), 1610 (CN Schiff base), 1584, 1525, 1486, 1476, 1436, 1313, 1267, 1212, 1146, 1029, 823, 753, 729, 695; elemental analysis calculated for $\mathrm{C}_{54} \mathrm{H}_{41} \mathrm{IrN}_{4} \mathrm{O}_{2}$ (970.29 g/mol): C 66.85\%, H 4.26\%, N 5.78\%, found: C $66.80 \%, \mathrm{H} 4.14 \%, \mathrm{~N} 5.82 \%$.
5.3. Synthesis of Intermediate Complex 2. To a degassed aqueous solution $(10 \mathrm{~mL})$ of $\mathrm{IrCl}_{3} \cdot x \mathrm{H}_{2} \mathrm{O}(93 \mathrm{mg}, 0.25 \mathrm{mmol})$, 2 eqs. of $\mathbf{H}(\mathbf{B z T h}$-tpa) [23] (200 $\mathrm{mg}, 0.50 \mathrm{mmol})$ solubilized in $30 \mathrm{~mL}$ of degassed ethoxyethanol is added. The reaction mixture was refluxed for 4 days under inert atmosphere $\left(\mathrm{N}_{2}\right)$. A brown solid is filtered off and washed with distilled water and ethanol and dried under vacuum.

Brown solid; yield $40 \%$ (96 mg); m.p. $>250{ }^{\circ} \mathrm{C} ;{ }^{1} \mathrm{H}$ NMR $\left(\mathrm{CDCl}_{3}, 300 \mathrm{MHz}, \mathrm{TMS}\right) \delta=8.62(\mathrm{~d}, J=6.0 \mathrm{~Hz}, 2 \mathrm{H}), 7.27$ $(\mathrm{d}, J=1.23 \mathrm{~Hz}, 2 \mathrm{H}), 7.05-7.03(\mathrm{~m}, 4 \mathrm{H}), 6.95-6.91(\mathrm{~m}, 10 \mathrm{H})$, 6.84-6.81 (m, 4H), 6.70-6.68 (m, 8H), $6.46(\mathrm{dd}, J=8.45 \mathrm{~Hz}$, $J=2.04 \mathrm{~Hz}, 2 \mathrm{H}), 5.48(\mathrm{~d}, J=2.19 \mathrm{~Hz}, 2 \mathrm{H})$; FT-IR $(\mathrm{KBr}$, $\left.\mathrm{cm}^{-1}\right): 1571,1498,1459,1429,1378,1262,1096,1022,802,749$, 694, 508; elemental analysis calculated for $\mathrm{C}_{50} \mathrm{H}_{34} \mathrm{Cl}_{2} \mathrm{Ir}_{2} \mathrm{~N}_{4} \mathrm{~S}_{2}$ : C $49.54 \%$, H 2.99\%, N 4.62\%, found: C 49.60\%, H 3.04\%, N $4.42 \%$.

5.4. Synthesis of Complex III. Intermediate complex 2 (75 mg, $0.038 \mathrm{mmol}$ ) was solubilized in $c a .50 \mathrm{~mL}$ of a $1: 1 \mathrm{mix}-$ ture of acetone and chloroform. 2 eqs. $(24 \mathrm{mg}, 0.076 \mathrm{mmol})$ of $\mathbf{H}\left(\mathbf{O}^{\wedge} \mathbf{N}\right)_{\mathbf{C 6}}$ [21] and 30 eqs. $(0.06 \mathrm{~mL}, 0.9 \mathrm{mmol})$ of trimethylamine were added to the solution. The reaction mixture was stirred at reflux for $48 \mathrm{~h}$. and at r.t. for $48 \mathrm{~h}$. The solvent was evaporated and the organic phase extracted with dichloromethane/water and dried over sodium sulphate. The crude product was purified by precipitation from dichloromethane/cold ethanol. The solid was filtrated, washed with cold methanol, and dried under vacuum.

Red-brown solid; yield 55\% (53 mg), m.p. > 250 ${ }^{\circ} ;{ }^{1} \mathrm{H}$ $\operatorname{NMR}\left(\mathrm{CDCl}_{3}, 300 \mathrm{MHz}, \mathrm{TMS}\right) \delta=8.43(\mathrm{~d}, J=9.09 \mathrm{~Hz}, 1 \mathrm{H})$, $8.01(\mathrm{~d}, J=9.24 \mathrm{~Hz}, 1 \mathrm{H}), 7.91(\mathrm{~s}, 1 \mathrm{H}), 7.59(\mathrm{~d}, J=7.62 \mathrm{~Hz}, 2 \mathrm{H})$, $7.39(\mathrm{~d}, J=8.49 \mathrm{~Hz}, 1 \mathrm{H}), 7.20(\mathrm{~d}, J=9.39 \mathrm{~Hz}, 4 \mathrm{H}), 7.09-6.95$ $(\mathrm{m}, 7 \mathrm{H}), 6.89-6.82(\mathrm{~m}, 10 \mathrm{H}), 6.69(\mathrm{~d}, J=9.3 \mathrm{~Hz}, 3 \mathrm{H}), 6.63(\mathrm{~d}$, $J=8.07 \mathrm{~Hz}, 3 \mathrm{H}), 6.50(\mathrm{dd}, J=8.43 \mathrm{~Hz}, J=2.2 \mathrm{~Hz}, 1 \mathrm{H}), 6.47$ $(\mathrm{d}, J=3.09 \mathrm{~Hz}, 1 \mathrm{H}), 6.34(\mathrm{~d}, J=8.49 \mathrm{~Hz}, 2 \mathrm{H}), 6.16(\mathrm{~d}, J=$ $8.07 \mathrm{~Hz}, 3 \mathrm{H}), 5.86(\mathrm{~d}, J=2.05 \mathrm{~Hz}, 1 \mathrm{H}), 5.70(\mathrm{~d}, J=2.07 \mathrm{~Hz}$, $1 \mathrm{H}), 3.62\left(\mathrm{~s}, 3 \mathrm{H},-\mathrm{OCH}_{3}\right), 2.42(\mathrm{~m}, 2 \mathrm{H}), 1.27(\mathrm{~m}, 8 \mathrm{H}), 0.91(\mathrm{t}$, $J=6.6 \mathrm{~Hz}, 3 \mathrm{H})$; FT-IR $\left(\mathrm{KBr}, \mathrm{cm}^{-1}\right): 1584,1571,1483,1459$, $1429,1261,1095,1021,865,801,751,694$; elemental analysis calculated for $\mathrm{C}_{70} \mathrm{H}_{58} \mathrm{IrN}_{5} \mathrm{O}_{2} \mathrm{~S}_{2}(1257.59 \mathrm{~g} / \mathrm{mol})$ : C $66.85 \%, \mathrm{H}$ 4.65\%, N 5.57\%, found: C 66.90\%, H 4.064\%, N 5.59\%.

5.5. Synthesis of Complex IV. Complex IV was prepared following the same procedure reported for complex III with the following modifications: intermediate $2(96 \mathrm{mg}, 0.048 \mathrm{mmol})$ and 2 eqs. of $\mathbf{H}\left(\mathbf{O}^{\wedge} \mathbf{N}\right)_{\text {tpa }}$ [18] (46 mg, $\left.0.096 \mathrm{mmol}\right)$ were treated with 30 eqs. of trimethylamine $(86 \mathrm{mg}, 1.44 \mathrm{mmol})$.

Brown solid; yield: $51 \%(70 \mathrm{mg})$; m.p. $>250{ }^{\circ} \mathrm{C} ;{ }^{1} \mathrm{H}$ NMR $\left(\mathrm{CDCl}_{3}, 300 \mathrm{MHz}, \mathrm{TMS}\right) \delta=8.44(\mathrm{~d}, J=8.37 \mathrm{~Hz}, 1 \mathrm{H}), 8.05$ $(\mathrm{d}, J=7.14 \mathrm{~Hz}, 1 \mathrm{H}), 7.98(\mathrm{~s}, 1 \mathrm{H}), 7.61(\mathrm{t}, J=6.59 \mathrm{~Hz}, 3 \mathrm{H})$, $7.41(\mathrm{~d}, J=8.64 \mathrm{~Hz}, 2 \mathrm{H}), 7.20-6.80(\mathrm{~m}, 36 \mathrm{H}), 6.72(\mathrm{~d}, J=$ $9.06 \mathrm{~Hz}, 4 \mathrm{H}), 6.52(\mathrm{~d}, J=10.83 \mathrm{~Hz}, 4 \mathrm{H}), 6.33(\mathrm{t}, J=9.33 \mathrm{~Hz}$, $4 \mathrm{H}), 5.86(\mathrm{~d}, J=2.19 \mathrm{~Hz}, 1 \mathrm{H}), 5.73(\mathrm{~d}, J=1.53 \mathrm{~Hz}, 1 \mathrm{H})$, $3.65\left(\mathrm{~s}, 3 \mathrm{H},-\mathrm{OCH}_{3}\right)$; FT IR $\left(\mathrm{KBr}, \mathrm{cm}^{-1}\right)$ : 1572, 1526, 1490, 1460, 1386, 1268, 1172, 1144, 1067, 822, 751, 695, 509; elemental analysis calculated for $\mathrm{C}_{82} \mathrm{H}_{59} \mathrm{IrN}_{6} \mathrm{O}_{2} \mathrm{~S}_{2}$ (1416.73 g/mol): C $69.52 \%, \mathrm{H} 4.20 \%$, N 5.93\%, found: C $69.60 \%, \mathrm{H} 4.30 \%$, N $6.01 \%$. 


\section{Conflict of Interests}

The authors declare that there is no conflict of interests regarding the publication of this paper.

\section{Acknowledgment}

This work was supported through the European Community's Seventh Framework Program (FP7 2007-2013) by Regione Calabria (POR CALABRIA FESR 2007/2013, ASSE I).

\section{References}

[1] C.-L. Ho and W.-Y. Wong, "Metal-containing polymers: facile tuning of photophysical traits and emerging applications in organic electronics and photonics," Coordination Chemistry Reviews, vol. 255, no. 21-22, pp. 2469-2502, 2011.

[2] F. S. Arimoto and A. C. Haven Jr., "Derivatives of dicyclopentadienyliron," Journal of the American Chemical Society, vol. 77, no. 23, pp. 6295-6297, 1955.

[3] G. R. Whittell and I. Manners, "Metallopolymers: new multifunctional materials," Advanced Materials, vol. 19, no. 21, pp. 3439-3468, 2007.

[4] A. Maier, A. R. Rabindranath, and B. Tieke, "Fast-switching electrochromic films of zinc polyiminofluorene-terpyridine prepared upon coordinative supramolecular assembly," $A d-$ vanced Materials, vol. 21, no. 9, pp. 959-963, 2009.

[5] S. Nagappan, S. S. Park, E. J. Yu et al., "A highly transparent, amphiphobic, stable and multi-purpose poly(vinyl chloride) metallopolymer for anti-fouling and anti-staining coatings," Journal of Materials Chemistry A, vol. 1, no. 39, pp. 12144-12153, 2013.

[6] B. Schulze, C. Friebe, S. Hoeppener et al., "Ruthenium(II) metallo-supramolecular polymers of click-derived tridentate ditopic ligands," Macromolecular Rapid Communications, vol. 33, no. 6-7, pp. 597-602, 2012.

[7] H. S. White, J. Leddy, and A. J. Bard, "Polymer films on electrodes. 8. Investigation of charge-transport mechanisms in Nafion polymer modified electrodes," Journal of the American Chemical Society, vol. 104, no. 18, pp. 4811-4817, 1982.

[8] Y.-W. Zhong, C.-J. Yao, and H.-J. Nie, "Electropolymerized films of vinyl-substituted polypyridine complexes: synthesis, Characterization, and applications," Coordination Chemistry Reviews, vol. 257, no. 7-8, pp. 1357-1372, 2013.

[9] H. D. Abruña, P. Denisevich, M. Umaña, T. J. Meyer, and R. W. Murray, "Rectifying interfaces using two-layer films of electrochemically polymerized vinylpyridine and vinylbipyridine complexes of ruthenium and iron on electrodes," Journal of the American Chemical Society, vol. 103, no. 1, pp. 1-5, 1981.

[10] J. Hjelm, R. W. Handel, A. Hagfeldt, E. C. Constable, C. E. Housecroft, and R. J. Forster, "Conducting polymers containing in-chain metal centers: electropolymerization of oligothienylsubstituted $\{\mathrm{M}($ tpy $) 2\}$ complexes and in situ conductivity studies, $\mathrm{M}=\mathrm{Os}(\mathrm{II}), \mathrm{Ru}(\mathrm{II})$," Inorganic Chemistry, vol. 44, no. 4, pp. 1073-1081, 2005.

[11] X.-Y. Chen, X. Yang, and B. J. Holliday, "Photoluminescent europium-containing inner sphere conducting metallopolymer," Journal of the American Chemical Society, vol. 130, no. 5, pp. 1546-1547, 2008.
[12] K. Foster and T. McCormac, "Synthesis, characterization and electrochemical polymerization of a $\mathrm{Ru}^{2+}$ functionalized pyrrole monomer," Electroanalysis, vol. 19, no. 14, pp. 1509-1517, 2007.

[13] C. D. Ellis, L. D. Margerum, R. W. Murray, and T. J. Meyer, "Oxidative electropolymerization of polypyridyl complexes of ruthenium," Inorganic Chemistry, vol. 22, no. 9, pp. 1283-1291, 1983.

[14] K. L. Brown and H. A. Mottola, "Voltammetric, chronocoulometric, and spectroelectrochemical studies of electropolymerized films based on $\mathrm{Cu}(\mathrm{II} / \mathrm{I})-4,9,16,23$-tetraaminophthalocyanine," Langmuir, vol. 14, no. 12, pp. 3411-3417, 1998.

[15] A. Venkatanarayanan, A.-M. Spehar-Délèze, L. Dennany, Y. Pellegrin, T. E. Keyes, and R. J. Forster, "Ruthenium aminophenanthroline metallopolymer films electropolymerized from an ionic liquid: deposition and electrochemical and photonic properties," Langmuir, vol. 24, no. 19, pp. 11233-11238, 2008.

[16] M.-K. Leung, M.-Y. Chou, Y. O. Su et al., "Diphenylamino group as an effective handle to conjugated donor-acceptor polymers through electropolymerization," Organic Letters, vol. 5, no. 6, pp. 839-842, 2003.

[17] D. Qiu, Q. Zhao, X. Bao et al., "Electropolymerization and characterization of an alternatively conjugated donor-acceptor metallopolymer: poly-[Ru(4'-(4-(Diphenylamino)phenyl)-2,2 $: 6^{\prime}$, $2^{\prime \prime}$-Terpyridine $\left.)_{2}\right]^{2+}$," Inorganic Chemistry Communications, vol. 14, no. 1, pp. 296-299, 2011.

[18] A. Ionescu, R. Lento, T. F. Mastropietro et al., "Electropolymerized highly photoconductive thin films of cyclopalladated and cycloplatinated complexes," ACS Applied Materials \& Interfaces, vol. 7, no. 7, pp. 4019-4028, 2015.

[19] H.-J. Yen and G.-S. Liou, "Solution-processable triarylaminebased electroactive high performance polymers for anodically electrochromic applications," Polymer Chemistry, vol. 3, no. 2, pp. 255-264, 2012.

[20] J. Pommerehne, H. Vestweber, W. Guss et al., "Efficient two layer LEDs on a polymer blend basis," Advanced Materials, vol. 7, no. 6, pp. 551-554, 1995.

[21] A. M. Talarico, E. I. Szerb, T. F. Mastropietro, I. Aiello, A. Crispini, and M. Ghedini, "Tuning solid state luminescent properties in a hydrogen bonding-directed supramolecular assembly of bis-cyclometalated iridium(III) ethylenediamine complexes," Dalton Transactions, vol. 41, no. 16, pp. 4919-4926, 2012.

[22] M. Ghedini, A. Golemme, I. Aiello et al., "Liaisons between photoconductivity and molecular frame in organometallic Pd(ii) and Pt(ii) complexes," Journal of Materials Chemistry, vol. 21, no. 35, pp. 13434-13444, 2011.

[23] Y. Zhang, M. Song, and L. Huang, "A novel blue-emitting $\operatorname{Ir}(\mathrm{III})$ complex with short excited state lifetime: synthesis, structure, photophysical property, and electrophosphorescence performance," Journal of Luminescence, vol. 132, no. 9, pp. 2242 2246, 2012.

[24] C. Fan, L. Zhu, B. Jiang et al., "High power efficiency yellow phosphorescent OLEDs by using new iridium complexes with halogen-substituted 2-phenylbenzo[d] thiazole ligands," Journal of Physical Chemistry C, vol. 117, no. 37, pp. 19134-19141, 2013.

[25] J. Natera, L. Otero, L. Sereno et al., "A novel electrochromic polymer synthesized through electropolymerization of a new donor-acceptor bipolar system," Macromolecules, vol. 40, no. 13, pp. 4456-4463, 2007. 

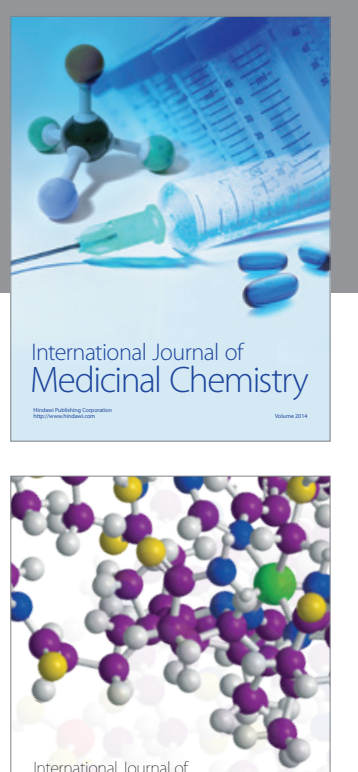

Carbohydrate Chemistry

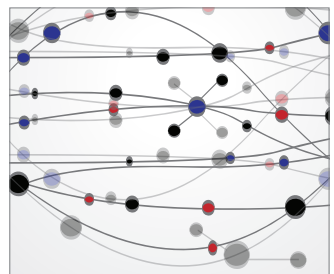

The Scientific World Journal
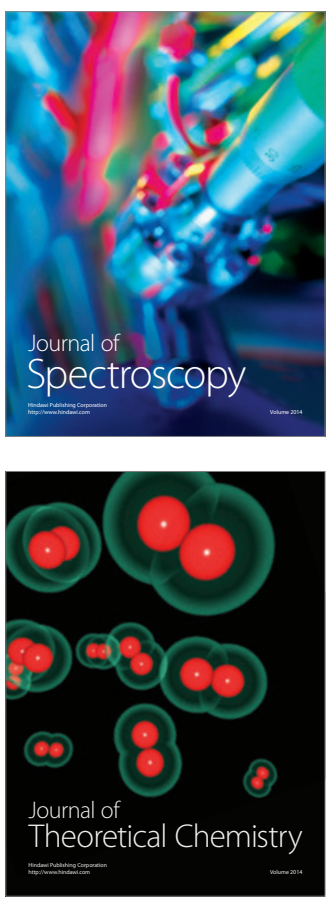
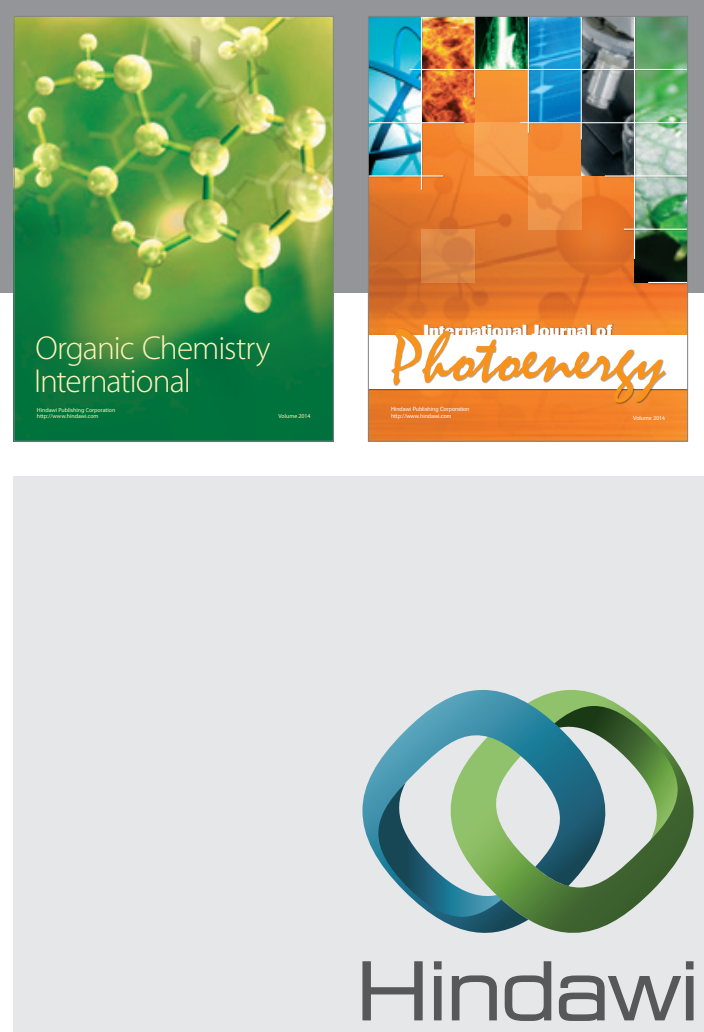

Submit your manuscripts at

http://www.hindawi.com

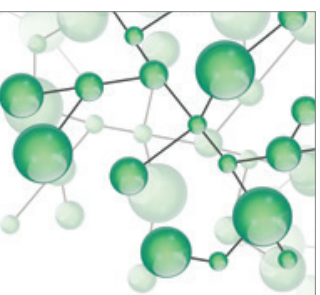

International Journal of

Inorganic Chemistry

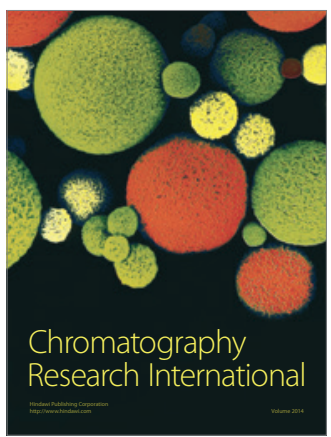

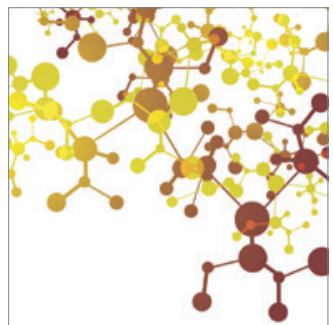

Applied Chemistry
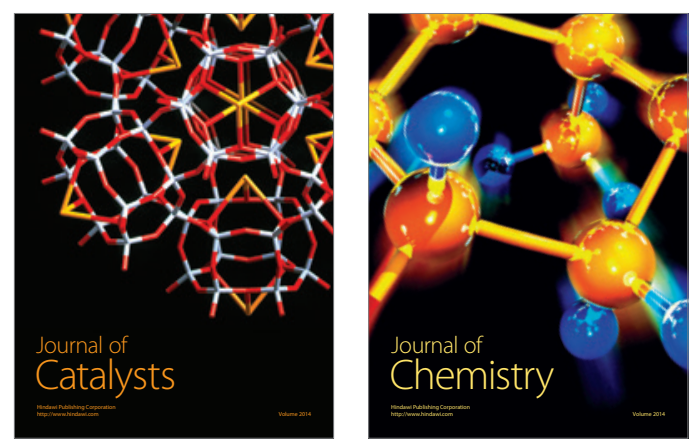
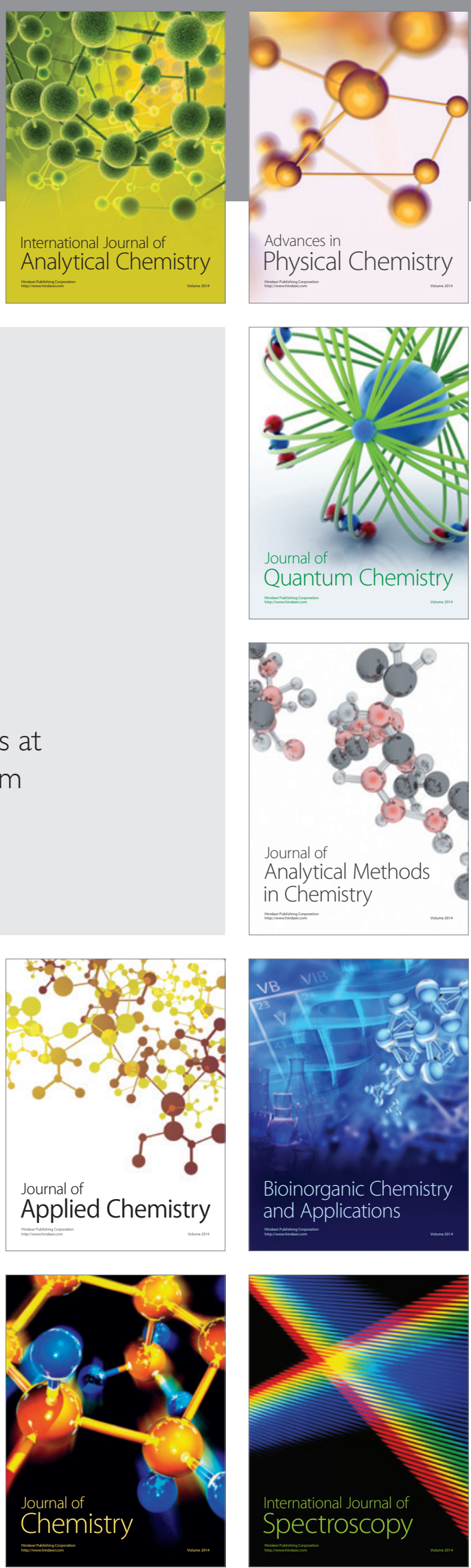